\title{
Floral Phenology of Upper Amazon Cocoa Trees: Implications for Reproduction and Productivity of Cocoa
}

\author{
M. K. Adjaloo, ${ }^{1}$ W. Oduro, ${ }^{2}$ and B. K. Banful ${ }^{3}$ \\ ${ }^{1}$ Technology Consultancy Centre, College of Engineering, KNUST, Kumasi, Ghana \\ ${ }^{2}$ Department of Wildlife and Range Management, Faculty of Renewable Natural Resources, \\ College of Agriculture and Natural Resources, KNUST, Kumasi, Ghana \\ ${ }^{3}$ Department of Horticulture, Faculty of Agriculture, College of Agriculture and Natural Resources, KNUST, \\ Kumasi, Ghana
}

Correspondence should be addressed to M. K. Adjaloo, mkadjaloo@gmail.com

Received 18 April 2012; Accepted 5 June 2012

Academic Editors: D. J. Cherney and M. Ruiz

Copyright (c) 2012 M. K. Adjaloo et al. This is an open access article distributed under the Creative Commons Attribution License, which permits unrestricted use, distribution, and reproduction in any medium, provided the original work is properly cited.

A study of the floral phenology of cocoa trees was carried out between 2006 and 2008 at Kubease in the Ashanti Region of Ghana, using one hundred cocoa trees from ten farm plots. The objective was to assess the contribution of floral phenology to the productivity of cocoa. Cocoa like all tropical tree species exhibited seasonally-related phenological patterns involving overlapping cycles under both intrinsic and extrinsic controls. However, unlike most tropical plants, flowering was in the rainy season. The production of new pods or cherelles increased during the major rainy season (June, July, and August), but was evenly distributed from the minor to the dry season. Production of small and medium pods peaked in August whereas production of large pods peaked in October. There was a positive correlation between new pod production and pods abortion $(r=0.69 ; n=100 ; P<0.05)$. Temperature, light intensity, and rainfall positively affected production of floral buds and production of open flowers. However, rainfall had the greatest influence on the phenological cycle of the cocoa plant. The floral phenological pattern also coincided with the activity of the main pollinators of cocoa which resulted in enhanced reproductive capacity for increased production of cocoa.

\section{Introduction}

Cocoa (Theobroma cacao L.) ranks number three in global export commodities after coffee and sugar and is a major cash crop in many tropical countries [1]. Produced on more than 7.5 million hectares, cocoa provides a means of livelihood for an estimated 40 million people worldwide, ranging from small holder farmers, laborers to employees in processing factories. In the lowland tropics, including parts of Latin America, West Africa, and Indonesia, cocoa is a crop grown largely by smallholder farmers (smallholdings of less than ten hectares) [2]. Compared to other agricultural activities, cocoa has been a leading subsector in the economic growth and development of several West African countries including Ghana [3]. World cocoa production increased at a rate of 2.2 percent a year, from 1998 to 2010 culminating in a production level of 3.7 million tons over the period [4]. Studies in other parts of the world suggest that the yield of cocoa is related to the floral phenology of the trees $([5,6])$. Clarke [7] reported that a good understanding of the floral phenology of tree crops provides significant insights into the functional attributes of growth and reproduction of the trees. Therefore, the synchronization between the phenology of flowering of cocoa trees and the pollinator population cycle, will constitute a significant step towards the realization of increased yield of cocoa. To our knowledge, however, there is not much information in Ghana on the floral phenology of the cocoa tress that could enhance the production potential of the trees for increased economic returns. Consequently, cocoa tree floral studies were carried out on the Amazonian variety in one of the major cocoa growing areas in the Ashanti region of Ghana to determine the floral phenology 
pattern and its relation to reproduction and productivity of the popularly cultivated Amazonian cocoa.

\section{Methodology}

2.1. The Biophysical Characteristics of the Study Area. The study location called Kubease in the Ejisu-Juabeng District of the Ashanti Region of Ghana (Figure 1) lies between latitudes $6^{\circ} 44^{\prime}$ and $6^{\circ} 40^{\prime}$ North and longitudes $1^{\circ} 15^{\prime}$ and $1^{\circ} 22^{\prime}$ West (source: Gold Coast Survey Field Sheet No. 129, Scale $1: 62,500$ ), and it is about 180 to $240 \mathrm{~m}$ above sea level. The natural forest belongs to the Triplochiton-Celtis of the tropical moist semideciduous formation [8]. The area has an annual average temperature of $26.5( \pm 2.09)^{\circ} \mathrm{C}$, relative humidity of $86.1( \pm 12.6) \%$, and a mean monthly rainfall ranging between $19.1-235.1 \mathrm{~mm}$. The area experiences a bimodal rainfall distribution, with peaks in June and September. The first and second growing seasons typically last from mid-March to mid-July and from mid-August to end of November, respectively, separated by a short dry spell of about four weeks in July. The major dry season starts in mid-November and lasts till end of March.

The climate is marked by high incidence of solar radiation and relatively little variation in day length.

2.2. Experimental Procedure. Ten farmer-managed cocoa farms were used in the study. In each farm, ten adult cocoa trees within a $400 \mathrm{~m}^{2}$ dimension were randomly selected and tagged using red ribbon. The total number of adult cocoa trees used for the study therefore was one hundred.

For three consecutive flowering years (2006, 2007, and 2008) monthly examination was made on each tree for counts of flowers, buds, and fruit-set to determine their seasonality. The times of incidence of flower bud, flower opening, and fruit abortion were recorded as determinants of the final yield. Fifty cocoa trees on five study farms were studied each day, as this was the maximum number of trees that could be examined accurately within a single day for the relevant phenological data. For effective flower census on trees with height ranging from $5.42-11.52 \mathrm{~m}$, the protocol developed by the Cocoa Research Institute of Ghana for such tall trees was adopted [9]. Data collected included number of mature flower buds, open flowers, new pods or cherelles (which gave an estimate of pollination under field conditions), small pods (5-10 mm), medium pods (11$60 \mathrm{~mm})$, and large pods $(>60 \mathrm{~mm})$; numbers of diseased pods, number of aborted pods (or cherelle wilt) and a number of vertebrate (squirrel) attacked pods. The different pod sizes were counted to track changes in pod size over time and to determine which pod size had the most vertebrate damage.

2.3. Ambient Climatic Data. Data on temperature and relative humidity were measured by means of Data logger three times per habitat unit. The light intensity per study site was measured with Digital light meter (Extech model 401025) 0-2000 Foot Candle (Fc) range, under standardized conditions (i.e., on the ground and on sunny days, local time
$09.00 \mathrm{am})$. The percent canopy cover of cocoa tree stands was estimated using a Spherical Densiometer (R.E. Lemmon Forest Densiometers, USA). Rainfall data, were taken from the meteorological station of the Forestry Research Institute of Ghana, Kumasi.

2.4. Data Analysis. The count of flowers and other parameters taken were pooled together for all the ten farms. The flower count data were square-root $(\sqrt{x}+0.1)$ transformed before analysis. Data collected were subjected to Chi-Square analysis. To determine the relationship between climatic conditions (i.e. temperature, relative humidity, rainfall and light intensity) and flower production, regression analyses were performed.

\section{Results}

3.1. Phenological Pattern of Flowering in Cocoa. The overall phenological pattern of flowering of cocoa consisted of segmental flowering in repeated phases. Floral productions generally increased in the major rainy season which began in the month of April and peaked in July (Figure 2). During this period flowering was high and was borne in the canopy, on the branches and on trunks of the cocoa trees. Flowering generally reduced drastically in the minor rainy season from September to November and was restricted to the canopy and branches leaving the trunks with little or no flowers (Figure 2). From December which marked the beginning of the dry season, flowering was sparse even in the canopy whiles the trunks were completely flowerless. This trend continued throughout the dry season which ended in late March.

Flowering appeared to have been affected by the level of fruiting in the preceding year. About $40 \%$ of trees produced more fruits in the year 2006, leading to a good harvest by some farmers. In such situations there was late flowering of the trees in the ensuing year 2007 in spite of the onset of rains. Trees which had little fruiting in the previous year experienced early flowering. On the whole, the month with the most rain, was also the most productive month (Figure 2; Table 1).

There were many fluctuations in the floral abundance with peaks and declines in flower production. The production of new pods or cherelles increased during the major rainy season (June, July, and August), but was evenly distributed from the minor season through to the dry season (Figure 1). Fruit-set was low in April (2.4\%) but gradually increased till it peaked in September (173.6\%) (Figure 2; Table 1).

There was considerable tree-to-tree differences in the production of mature floral buds and open flowers (Table 1), such that the monthly total mature floral buds ranged from 34 to7246 (summed for all the 100 trees). Also the monthly totals of open flowers for the 100 trees ranged from 40 to 3818. A similar pattern was found in cherelles present at each monthly census, ranging from 102-2061 for all the 100 cocoa trees (Table 1). 


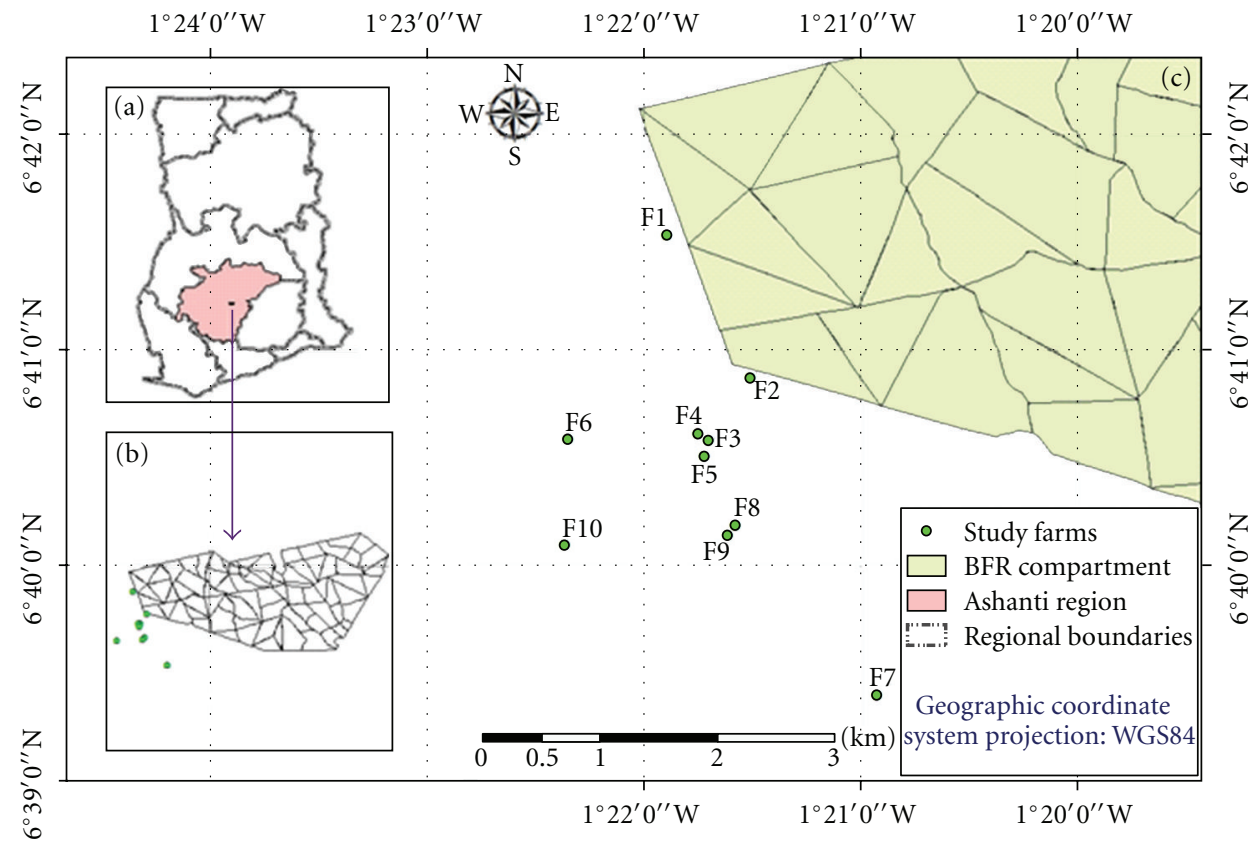

Figure 1: Map of the study Area in the Ejisu-Juabeng District of the Ashanti Region of Ghana.

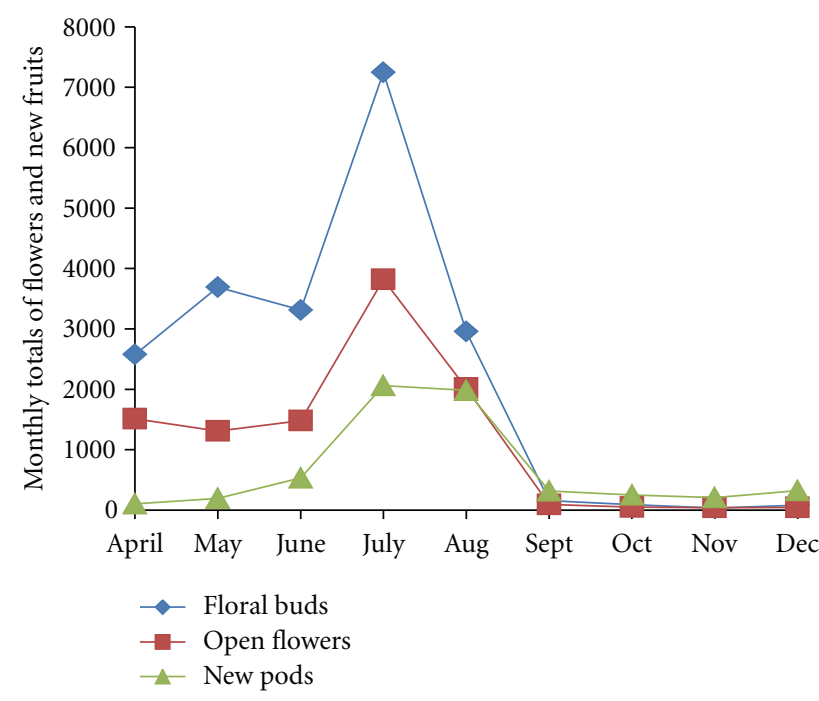

(a)

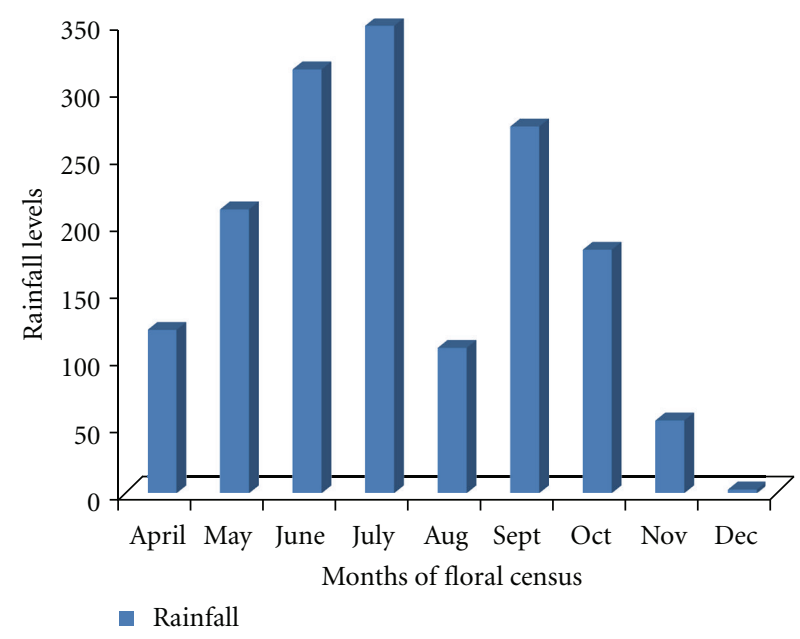

(b)

FIGURE 2: Phenological patterns of flower and fruit production in relation to rainfall pattern at Kubease in the Ejisu-Juabeng District.

There was highly significant $(P<0.001)$ differences in monthly floral production between the study farm plots although there were some overlaps in the level of production (Table 2). In addition, the monthly production of floral buds and open flowers also showed highly $(P<0.001)$ significant differences. Cherelle production levels were also significantly different $(P<0.05)$ in the months (Table 2$)$.

3.2. Fruit Production in Cocoa Trees. Fruit (small, medium, and large pods) production started in April and peaked in August. Comparing the fruit pod sizes, there were significant
$(P<0.001)$ differences in pod sizes between the months of the study (Figure 3 ).

Small pods, which formed about $80 \%$ of the total fruits produced peaked in production in August. Except in July, small pods production formed the highest number in all the remaining months. Significant production of medium and large pods started in July with the medium pods being in greater numbers than the large pods. Whereas medium pods production peaked in August, that of large pods peaked in October. The rate of production of new pods and pod losses through abortion was similar between the months of April and June. However, the rate of pod abortion greatly exceeded 
TABle 1: Phenological patterns of mature flower buds, open flowers, new pods, and percentage fruit-set of cocoa trees $(N=100)$ in ten farms at Kubease, in Ejisu-Juabeng District in 2005, 2006, and 2007.

\begin{tabular}{|c|c|c|c|c|c|c|c|}
\hline \multirow{2}{*}{$\begin{array}{l}\text { Census } \\
\text { Month }\end{array}$} & \multicolumn{2}{|c|}{ Mature floral buds } & \multicolumn{2}{|c|}{ Open flowers } & \multicolumn{2}{|c|}{ New pods } & \multirow{2}{*}{$\begin{array}{l}\text { Estimated } \\
\text { fruit-set } \%\end{array}$} \\
\hline & Total & Mean \pm SE & Total & Mean \pm SE & Total & Mean \pm SE & \\
\hline April & 2573 & $131.15 \pm 15.61$ & 1511 & $75.61 \pm 8.73$ & 102 & $5.12 \pm 0.71$ & 2.4 \\
\hline May & 3289 & $186.4 \pm 7.55$ & 1307 & $65.35 \pm 7.11$ & 194 & $9.73 \pm 1.12$ & 3.7 \\
\hline June & 3313 & $165.65 \pm 5.45$ & 1480 & $74.21 \pm 9.32$ & 532 & $26.61 \pm 3.14$ & 10.1 \\
\hline July & 7246 & $362.30 \pm 8.16$ & 3818 & $190.70 \pm 10.58$ & 2061 & $103.05 \pm 13.8$ & 15.7 \\
\hline August & 2955 & $147.75 \pm 6.08$ & 2018 & $100.90 \pm 8.60$ & 1982 & $104.11 \pm 11.61$ & 28.5 \\
\hline September & 157 & $7.85 \pm 3.26$ & 94 & $4.70 \pm 1.08$ & 317 & $17.05 \pm 2.37$ & 173.6 \\
\hline October & 89 & $4.45 \pm 0.51$ & 51 & $2.55 \pm 0.38$ & 252 & $13.40 \pm 2.37$ & 64.3 \\
\hline November & 34 & $1.77 \pm 0.16$ & 40 & $2.01 \pm 0.99$ & 206 & $10.31 \pm 3.06$ & 55.8 \\
\hline December & 82 & $4.25 \pm 0.11$ & 44 & $2.24 \pm 0.19$ & 322 & $16.15 \pm 3.80$ & 71.9 \\
\hline
\end{tabular}

TABLE 2: Flower and fruit production and pod losses averaged over ten cocoa farms at Kubease, Ejisu-Juabeng, Ghana.

\begin{tabular}{|c|c|c|c|c|c|c|c|c|}
\hline \multirow{2}{*}{ Months } & \multicolumn{8}{|c|}{ Census } \\
\hline & Mature flower bud & Open flower & New pods & Small pods & Medium pods & Large pods & Diseased pods & Aborted pods \\
\hline April & 1.6 & 0.7 & 0.5 & 0.8 & 0.3 & 0.3 & 0.4 & 1.1 \\
\hline May & 3.3 & 1.7 & 0.7 & 0.6 & 0.4 & 0.3 & 0.5 & 1.2 \\
\hline June & 4.3 & 2.5 & 1.1 & 0.8 & 0.4 & 0.3 & 0.5 & 1.4 \\
\hline July & 3.6 & 2.5 & 2.9 & 1.2 & 1.1 & 0.6 & 2.0 & 3.6 \\
\hline August & 2.1 & 1.6 & 2.6 & 1.8 & 1.3 & 0.6 & 2.6 & 3.9 \\
\hline September & 0.7 & 0.3 & 0.8 & 1.5 & 1.2 & 0.6 & 2.7 & 3.8 \\
\hline October & 0.8 & 0.4 & 1.1 & 1.6 & 1.1 & 0.6 & 2.6 & 3.8 \\
\hline November & 0.8 & 0.4 & 0.8 & 1.3 & 0.8 & 0.5 & 1.9 & 3.4 \\
\hline December & 0.8 & 0.4 & 1.2 & 0.8 & 0.5 & 0.5 & 0.6 & 1.7 \\
\hline$P$ value & 0.001 & 0.001 & 0.001 & 0.001 & 0.001 & 0.001 & 0.001 & 0.001 \\
\hline LSD (0.05) & 0.61 & 0.51 & 0.16 & 0.31 & 0.21 & 0.14 & 0.33 & 0.51 \\
\hline
\end{tabular}

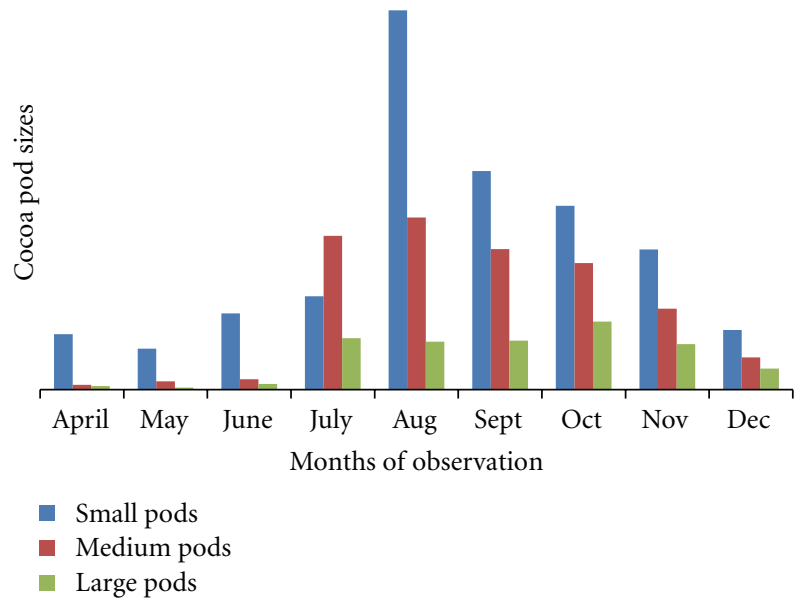

FIGURE 3: Changes in pod sizes during the study period.

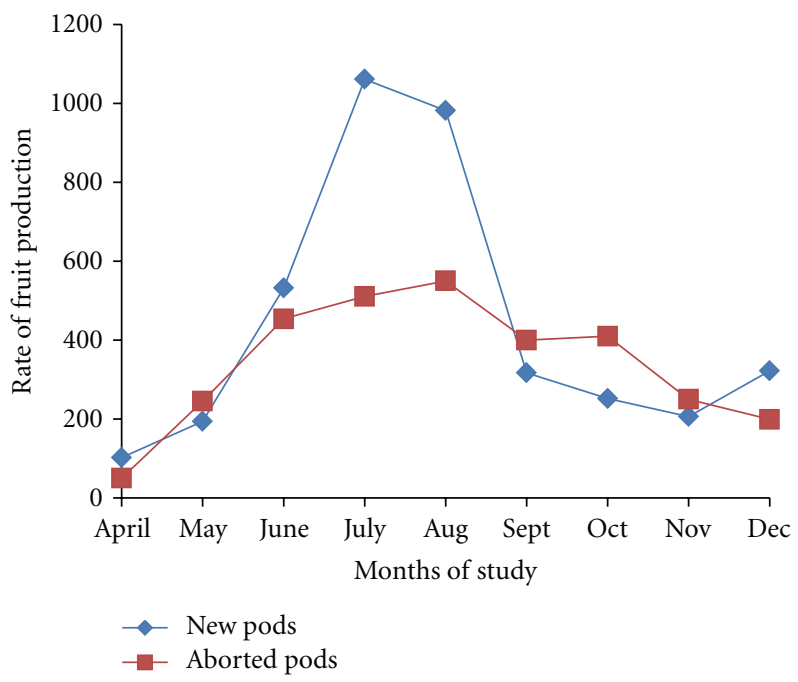

FIGURE 4: Levels of new pods and aborted fruits.

Between April and July, total fruit production and number of diseased pods were similar but deviated between August and October when the number of diseased pods exceeded total fruit production (Figure 5). the rate of new pods production from July to December (Figure 4). Generally, there was a positive and significant correlation between new pod production and pods abortion $(r=0.69 ; n=100 ; P<0.05)$. Aborted fruits are those with halted development and or with visible wilting. 


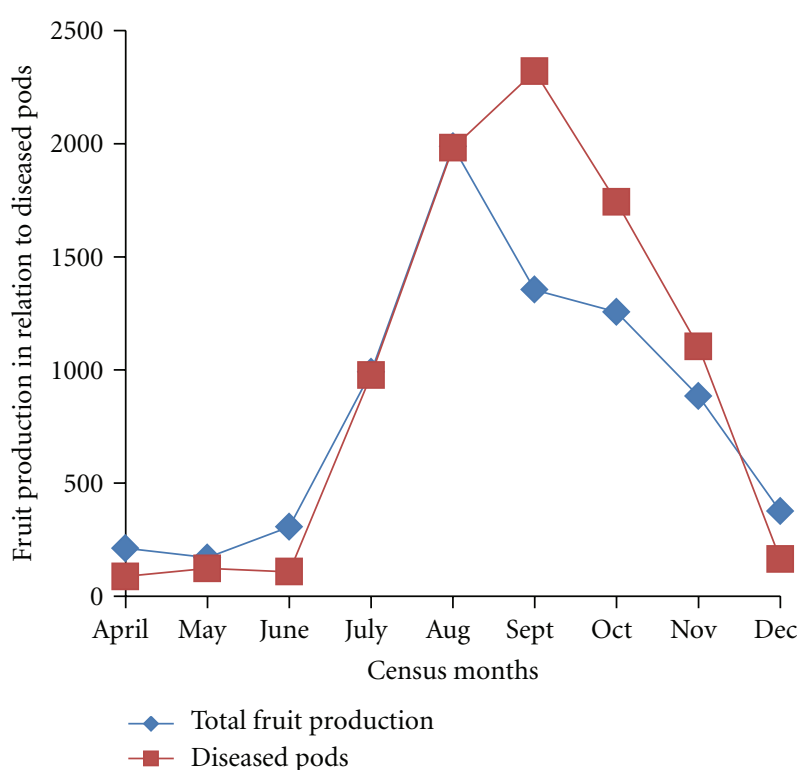

Figure 5: Contrast in fruit production and diseased pods.

3.3. Effect of Climatic Conditions on Flower Production. Significant relationships were found between flower production and climatic factors namely temperature, light intensity and rainfall. Temperature positively affected production of floral buds $\left(Y=83.75+28.03 X ; R^{2}=0.63\right)$ and production of open flowers $\left(Y=485+37.45 X ; R^{2}=0.72\right.$ ) (Figure 6). Similarly, light intensity affected production of floral buds $\left(Y=23.46+0.105 X ; R^{2}=0.62\right)$ and production of open flowers $\left(Y=18.09+0.068 X ; R^{2}=0.68\right)$ (Figure 8). In addition rainfall had a profound effect on floral buds production $\left(Y=24.497+0.139 X ; R^{2}=0.78\right)$ as well as the production of open flowers $\left(Y=15.95+0.9882 X ; R^{2}=0.75\right)$ (Figure 7). Comparing the three climatic factors, rainfall was found to have the greatest influence on the phenological cycle of the cocoa plant.

\section{Discussion}

4.1. Flowering Patterns. The present study has established that cocoa exhibits a season-related phenological pattern of flowering and fruit set involving overlapping cycles. Similar findings have been found in other tropical tree species [1013] emphasizing the fact that cocoa is no different from other tropical tree species. However, unlike most tropical plants whose period of least flowering is at the height of the long rainy season [13] cocoa presents a special case. Flowering, especially on the trunk was highest in the most rainy months. This may be due to intrinsic factors namely: genetic and physiological factors which appear to play a large role in the phenological behavior of the cocoa plant. The observation that flowering appeared to have been affected by the level of fruiting in the preceding year suggests a possible interyear linkage in resource use by leaves and fruit as suggested by Southwick [14] and Snow and Whigham [15]. The fruit of cocoa can contain over 400 times more energy than is stored in its flowers [16] thus highlighting the physiological importance of fruit abortion [17].

The observation that fruit production and fruit abortion increased during the rainy season is corroborated by Valle et al. [16]. The high incidence of fruit abortion (cherelle wilt) in cocoa during the flowering season is attributed to a physiological necessity of the tree itself $[18,19]$ and has been found in the present study to be the main cause of fruit loss. This physiological necessity is partially related to pollination intensity [19] and competition for nutritional resources $([16,20,21])$. Thus, fruit abortion is important in regulating the number of fruits per tree. By aborting fruits early in their development, plants conserve many of the necessary resources for future fruit and vegetative growth.

The tree-to-tree differences in the production of floral buds, opening of flowers, and formation of cherelles are consistent with the findings that cocoa flower initiation, shape and morphogenesis though dependent on the environment is regulated endogenously $[22,23]$. The monthly mean variations in the floral and fruit productions as well as fruit losses appeared to be the same during certain times of the year from September to December. During the dry seasons, flowering was either absent, very scanty on the trunk, or was limited to the inaccessible branches.

The observed levels of diseased pods in the area suggests that disease occurrence was a major determinant of final cocoa yield levels in commercial plantations, in spite of the fact that pollination successes largely determined the initial levels of fruit-set. This finding is in agreement with the observations made in La Lola, Costa Rica [12].

The Amazonia cocoa, the variety in the present study, has a longer spread of flowering due to the fact that the branches and trunks flower in turns, a phenomenon akin to the "manifold" (a term first used by [24]) leaf production in some tropical plants. Flowering starts on the tree trunk at the beginning of the rainy season but by the close of the year, the branches become the main flower-bearing part of the tree. This flowering behavior therefore allows for continuous pollination and fruiting. Consequently, harvesting of cocoa is not a one-time activity for the farmer but a series of activities which may begin from one year and end in the following year. Vaughton and Ramsey [25] have identified two proximate ecological mechanisms which account for this pattern that is, insufficient pollen delivery to stigmas and limited resources for maturation of fruits and seeds. This implies that effective pollination and adequate nutrition are critical for cocoa and as such authorities in the cocoa industry should focus attention on ensuring both effective pollination and nutrition provision. In practice, however, the authorities seem to place emphasis on nutrition and neglect pollination.

4.2. Effect of Climatic Conditions on Flower Production. Flowering of the cocoa trees in the study farms were affected by exogenous factors such as rainfall, temperature, and light. However, rainfall was found to be the most critical factor in the floral phenology of cocoa since it accounts for $78 \%$ and $75 \%$ of the variation in the production of mature floral 

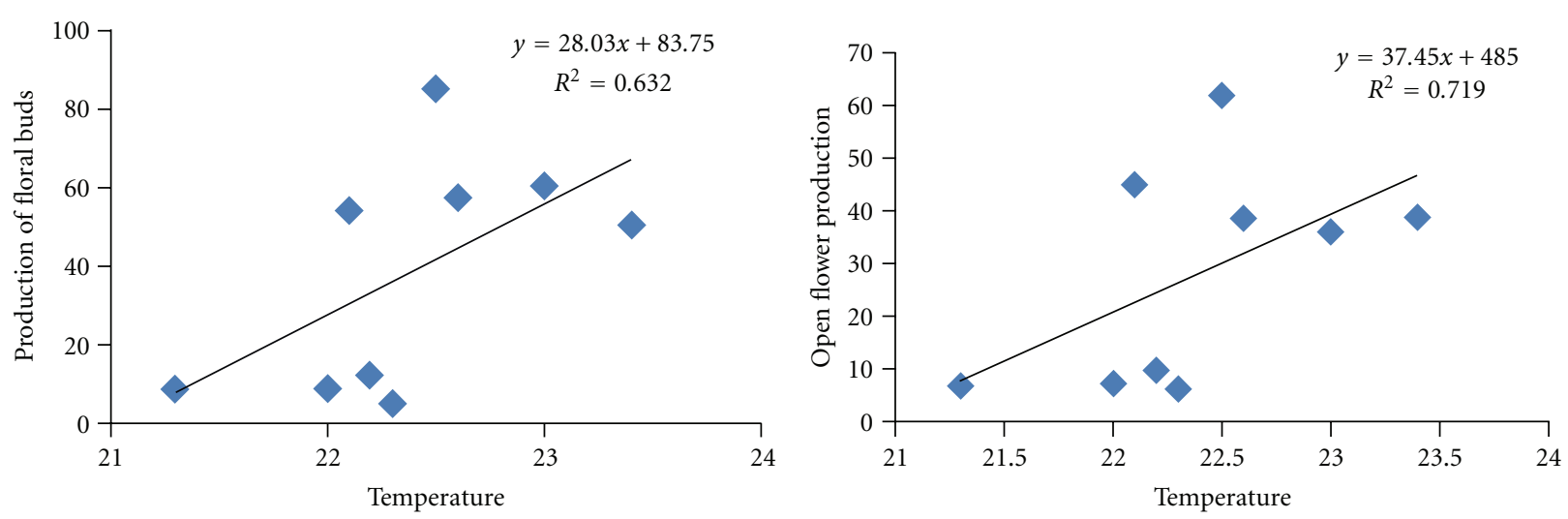

FIGURE 6: Relationship between temperature and the rate of mature floral buds, and open flowers. Data on the floral parts were square root transformed $(\sqrt{x}+0.1)$.
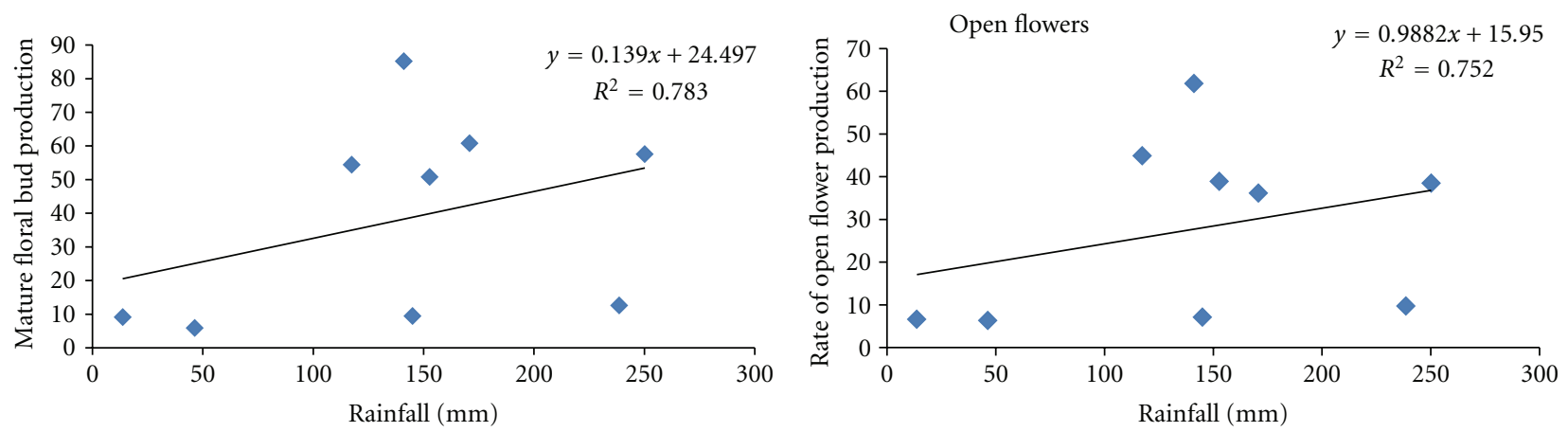

Figure 7: Effect of Rainfall on production of mature floral buds and open flowers. Data on the floral parts were square root transformed $(\sqrt{x}+0.1)$.

buds and open lowers, respectively. All the ten study farms were exposed to the sunlight as there were no shade trees, though there was self-shading in the mature trees due to unbroken canopies, thus modifying the light intensity and temperature. Absence of shade cover may condition cocoa trees throughout the year to flower at irregular intervals, that is, a phenological pattern far less indicative of a response to seasonal changes in rainfall and other climatic conditions $[10,12,18]$. It is assumed that in plants growing under unshaded conditions, the resulting greater leaf area due to vigorous leaf production, combined with higher light intensity may result in increased photosynthesis and increased carbohydrate production [26-28]. Flowering and abscission are some of the photomorphogenic (light-regulated growth) processes of cocoa and therefore makes light a critical factor. Low light intensities suppress flower production in cocoa [29], and high light intensity though detrimental to the photosynthetic apparatus of cocoa is reported to stimulate flowering [30, 31]. Omolaja et al. [23] observed that high temperature and increased rainfall promote flushing and flower initiation and flowering intensity in cocoa.

The fact that the cocoa flowered from the beginning of the raining season probably meant that cocoa reacts to the stimulus of water. This assertion was based on the observation that during the dry seasons (January through March) and before the onset of the rains in April there were no buds, flowers, or new pods on any of the tree trunks. It could be said generally that both genetic and physiological (intrinsic) factors are the primary factors responsible for basic timing of flowers whereas the environmental or extrinsic controls are the modifying factors. Ewusie [13] classified these factors, as proximal and distal factors respectively.

4.3. Implications of Cocoa Flowering Dynamics for Cocoa Reproduction and Productivity. The floral phenological patterns observed in the present study provide some advantage for cocoa reproduction and productivity. The main pollinators, biting midges (Ceratopogonidae), and gall midges (Cecidomyiidae), which are moisture-loving dipterans, are known to increase in population during the rainy months (May to July) when flower setting reaches a peak, and much less in the dry seasons [32]. Having more flowers in the rainiest months therefore could be a coevolutionary process to enhance its reproductive capacity as suggested by van Schaik et al. [33]. The issue of flower opening or anthesis at dawn might again be important to the pollination process as midge visits are known to start at dawn [32]. The present study has demonstrated that cocoa productivity could be 

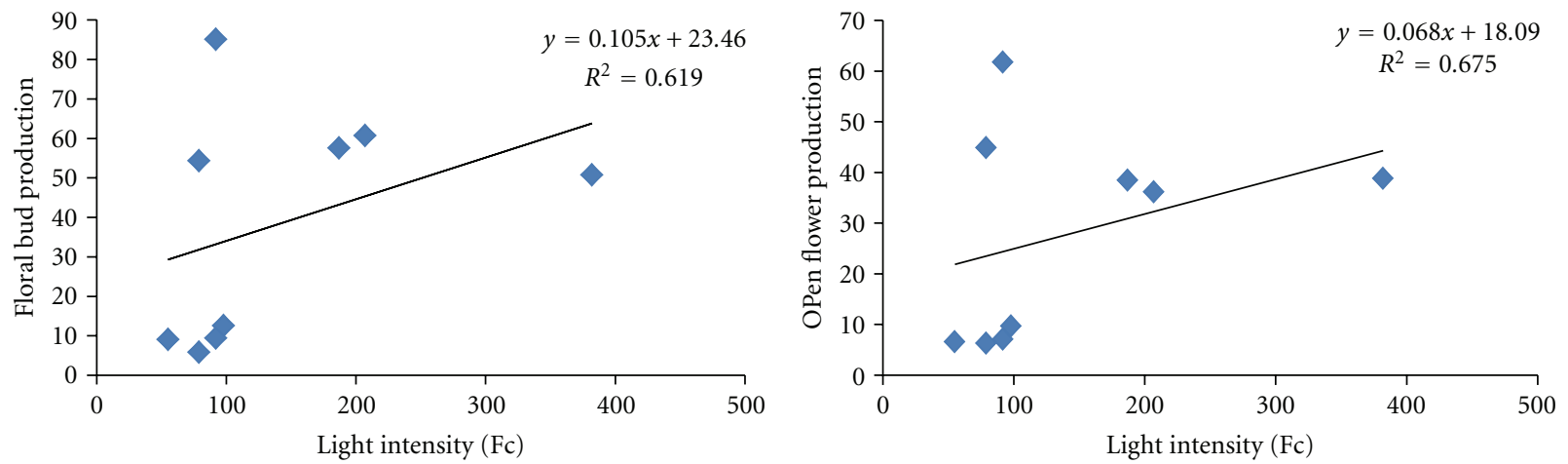

FIGURE 8: Effect of light intensity on production of mature floral buds and open flowers. Data on the floral parts were square root transformed $(\sqrt{x}+0.1)$.

seriously affected by flower drop due to no or insufficient pollination, diseases, and fruit abortion.

\section{Conclusion}

The study has demonstrated that cocoa like all tropical tree species in general exhibit season-related phenological patterns of flowering but unlike most tropical plants, flowering is at the height of the long rainy season. In addition, fruit-set involved overlapping cycles (the phenophases of flowering, fruiting, and leaf-formation and leaf-fall more than once a year) under both intrinsic and extrinsic controls. Rainfall, as an extrinsic factor, was found to be the most critical in the floral phenology. The floral phenological pattern coincided with the activity of the main pollinators of cocoa which resulted in enhanced reproductive capacity for increased production of cocoa.

\section{References}

[1] World Wildlife Fund, "Developing best practice guidelines for sustainable models of cocoa production. Maximize their impacts on biodiversity protection," Discussion Paper produced for WWF-Vietnam, 2006.

[2] M. Franzen and M. B. Mulder, "Ecological, economic and social perspectives on cocoa production worldwide," Biodiversity and Conservation, vol. 16, no. 13, pp. 3835-3849, 2007.

[3] B. Duguma, J. Gockowski, and J. Bakala, "Smallholder cacao (Theobroma cacao Linn.) cultivation in agroforestry systems of West and Central Africa: challenges and opportunities," Agroforestry Systems, vol. 51, no. 3, pp. 177-188, 2001.

[4] Food and Agricultural Organisation Commodity Projections to 2010 , pp. $73-74$.

[5] A. A. F. de Almeida and R. R. Valle, "Ecophysiology of the cacao tree," Brazilian Journal of Plant Physiology, vol. 19, no. 4, pp. 425-448, 2007.

[6] A. J. Daymond and P. Hadley, "Differential effects of temperature on fruit development and bean quality of contrasting genotypes of cacao (Theobroma cacao)," Annals of Applied Biology, vol. 153, no. 2, pp. 175-185, 2008.

[7] P. J. Clarke, "Baseline studies of temperate mangrove growth and reproduction: demographic and litterfall measures of leafing and flowering," Australian Journal of Botany, vol. 42, no. 1, pp. 37-48, 1994.
[8] J. B. Hall and M. D. Swaine, Distribution and Ecology of Vascular Plants in Tropical Rain Forest. Forest Vegetation in Ghana. Geobotany, Dr. W. Junk, 1981.

[9] J. E. Sarfo, B. Padi, F. M. Oppong, I. Y. Opoku, and A. Y. Akrofi, "Effects of two herbicides and four fungicides on insect pollination of cocoa," in Proceedings of the 14th International Cocoa Research Conference, vol. 2, pp. 1387-1392, Accra, Ghana, 20031983.

[10] P. Alvim de T., "Flowering of cocoa," Cocoa Growers' Bulletin, vol. 35, pp. 23-31, 1984.

[11] P. S. Ashton, T. J. Givnish, and S. Appanah, "Staggered flowering in the Dipterocarpaceae: new insights into floral induction and the evolution of mast fruiting in the aseasonal tropics," American Naturalist, vol. 132, no. 1, pp. 44-66, 1988.

[12] A. M. Young, "Cocoa pollination," Cocoa Growers' Bulletin, vol. 37, pp. 5-23, 1986.

[13] J. Y. Ewusie, Phenology in Tropical Ecology, Ghana Universities Press, Accra, Ghana, 1992.

[14] E. E. Southwick, "Photosynthate allocation to floral nectar: a neglected energy investment," Ecology, vol. 65, no. 6, pp. 17751779, 1984.

[15] A. A. Snow and D. F. Whigham, "Costs of flower and fruit production in Tipularia discolor (Orchidaceae)," Ecology, vol. 70, no. 5, pp. 1286-1293, 1989.

[16] R. R. Valle, A. A. F. de Almeida, and R. M. O. Leite, "Energy costs of flowering, fruiting and cherelle wilt in cacao," Tree Physiology, vol. 6, pp. 329-336, 1990.

[17] M. M. Bos, I. Steffan-Dewenter, and T. Tscharntke, "The relative importance of cacao fruit abortion,insect attacks and pathogens depends on shade tree management," Agriculture, Ecosystems and Environment. In press.

[18] A. M. Young, "Ecological notes on cacao-associated midges (Diptera: Ceratopogonidae) in the "Catongo" cacao plantation at Turrialba, Costa Rica," Proceedings of the Entomological Society of Washington, vol. 86, no. 1, pp. 185-194, 1984.

[19] M. Falque, A. Vincent, B. E. Vaissiere, and A. B. Eskes, "Effect of pollination intensity on fruit and seed set in cacao (Theobroma cacao L.)," Sexual Plant Reproduction, vol. 8, no. 6, pp. 354-360, 1995.

[20] G. Mossu, D. Paulin, and P. De Reffye, "Influence de la floraison et de la pollinisation sur les rendements du cacayer. Liaisons mathematiques entre les donnees experimentales. Equation du rendement," Café, Cacao, the, vol. 25, pp. 155$168,1981$. 
[21] G. A. R. Wood and R. A. Lass, Cacao, Longman, New York, NY, USA, 4th edition, 1985.

[22] H. Mohr and P. Schopfer, Plant Physiology, Springer, New York, NY, USA, 1994.

[23] S. S. Omolaja, P. Aikpokpodion, S. Adedeji, and D. E. Vwioko, "Rainfall and temperature effects on flowering and pollen productions in cocoa," African Crop Science Journal, vol. 17, no. 1, pp. 41-48, 2009.

[24] T. C. Whitmore, Tropical Rain Forest of the Far East, Oxford University Press, London, UK, 1975.

[25] G. Vaughton and M. Ramsey, "Pollinators and seed production," in Seed Development and Germination, J. Kigel and G. Galili, Eds., pp. 475-490, Marcel Dekker, NewYork, NY, USA, 1995.

[26] R. G. Hurd and R. K. Cunningham, "A cocoa shade and manurial experiment at the West Africa Cocoa Research Institute, Ghana. III. Physiological results," Journal of Horticultural Science, vol. 36, pp. 126-137, 1961.

[27] J. K. Owusu, "Light requirements of cocoa: a review," in Proceedings of the International Conference on Cocoa and Coconuts, pp. 112-121, Kuala Lumpur, Malaysia, 1978.

[28] S. J. Taylor and P. Hadley, "Relation between root and shoot growth in cocoa (Theobroma cacao) grown under different shade regimes," in Proceedings of the 10th International Cocoa Research Conference, pp. 77-183, Cocoa Producers Alliance, Santo Domingo, Dominican Republic, 1987.

[29] G. J. Anim-Kwapong, K. Opoku-Ameyaw, F. M. Amoah et al., "Cocoa agronomy: a review," Cocoa Research Insitute of Ghana, New Tafo-Akim, (unpublished).

[30] E. J. A. Asomaning, R. S. Kwakwa, and W. V. Hutcheon, "Physiological studies on an amazon shade and fertilizer trial at the Cocoa Reearch Institute of Ghana," Journal of Agricultural, vol. 4, pp. 47-64, 1971.

[31] S. T. Ampofo and E. E. N. A. Bonaparte, "Flushing, Flowering and pod-setting of hybrid cocoa in a cocoa shade/spacing/cultivar experiment," in Proceedings of the 7th International Cocoa Research Conference, pp. 103-108, Douala, Cameroon, 1981.

[32] A. H. Brew, "Cocoa pod husk as a breeding substrate for Forcipomyia midges and related species which pollinate cocoa in Ghana," 1988, Cocoa Growers Bulletin no. 40, November, 1988.

[33] C. P. van Schaik, J. W. Terborgh, and S. J. Wright, "The phenology of tropical forests: adaptive significance and consequences for primary consumers," Annual Review of Ecology and Systematics, vol. 24, pp. 353-377, 1993. 


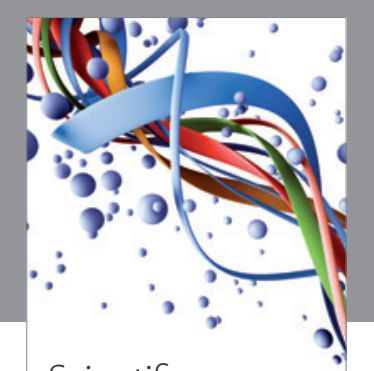

Scientifica
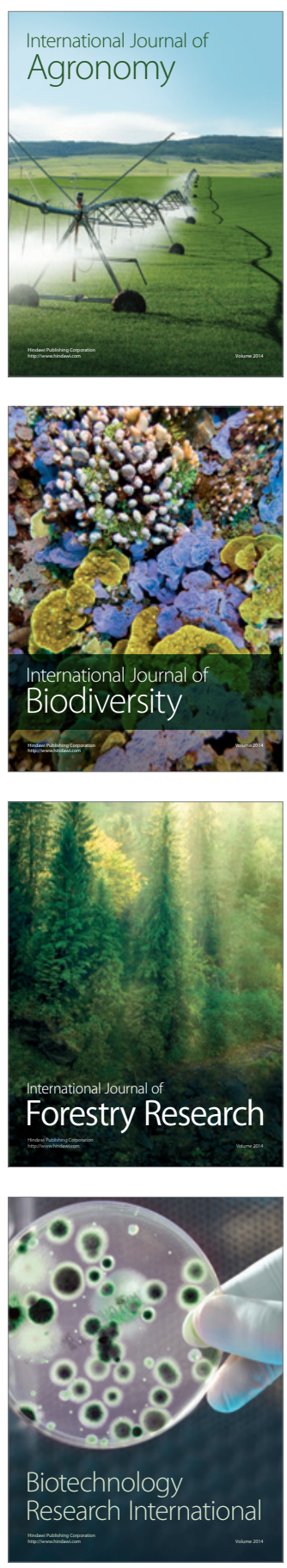
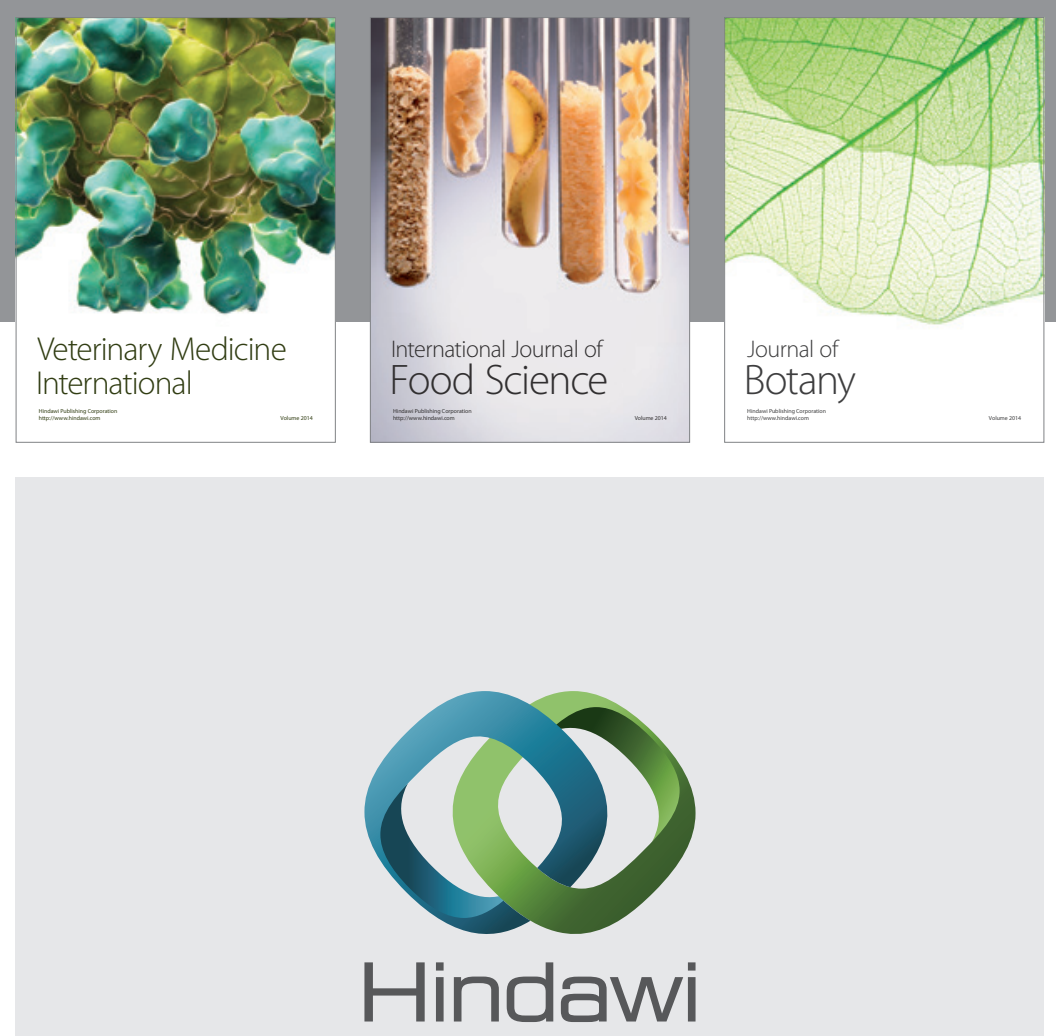

Submit your manuscripts at

http://www.hindawi.com
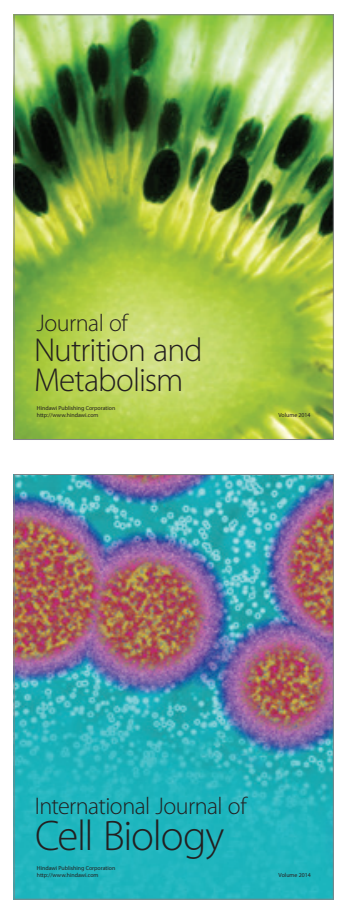
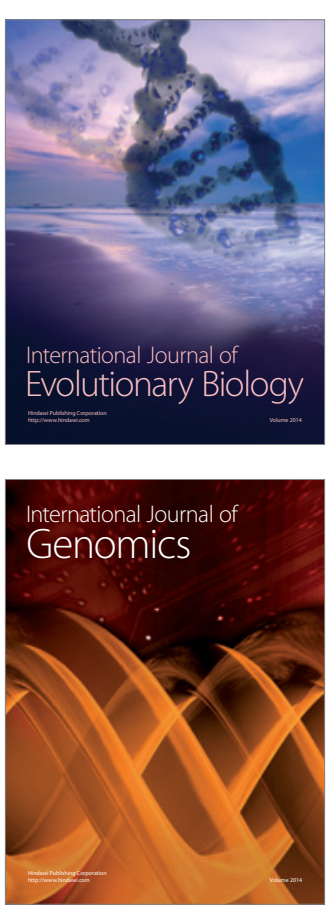
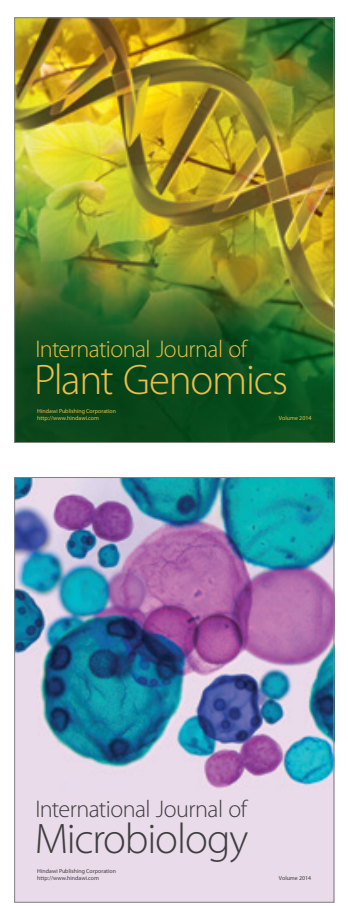

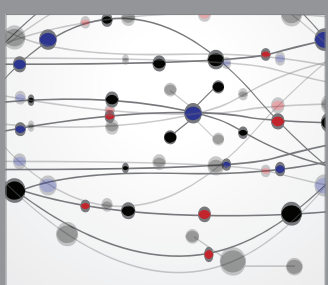

The Scientific World Journal
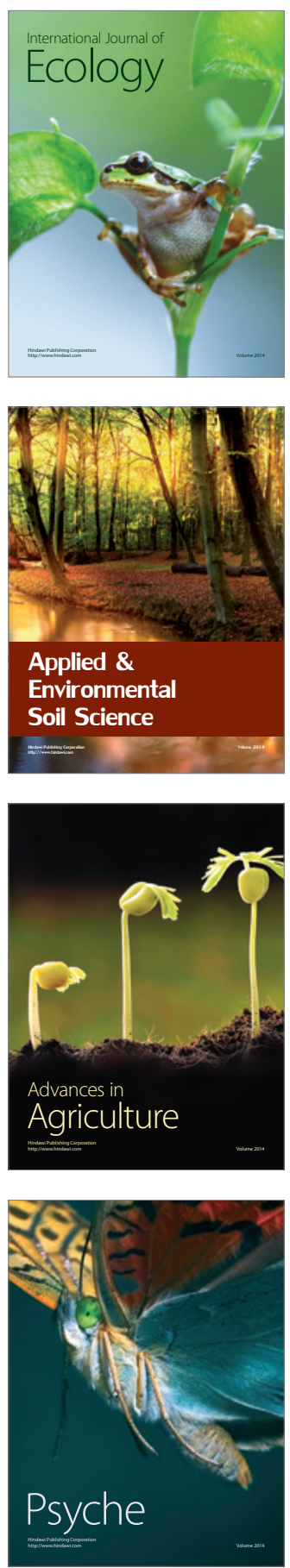